\title{
Simulation of Multipulse Convertor Using Control Rectifier
}

\author{
Gopal S.Panzade ${ }^{1}$, Hitesh Murkute ${ }^{2}$, Yogesh Likhar ${ }^{3}$, Prof. R.M.Bhombe ${ }^{4}$ \\ ${ }^{1}$ MTech, Department of Electrical, Guru Nanak Institute of Engineering and Technology, Nagpur, India \\ ${ }^{2,3,4}$ Professor, Department of Electrical, Guru Nanak Institute of Engineering and Technology, Nagpur, India.
}

Received on: 20 April, 2021, Revised on: 16 May, 2021, Published on: 18 May, 2021

\begin{abstract}
Power electronics used as harmonic switching when produced in line. These harmonics brought on dangerous influence on transmission line like dipping of voltage, it additionally minimized the efficiency and lifetime of equipment's. In this have a look at offers line commutated controlled multiples converters for fixing the harmonic trouble. The results of increasing the amount of pulses on the performance of $A C$ to DC converters were analyzed. Important factors to consider for efficiency evaluation are wavelength, morphological factor, and absolute harmonic distortion (THD). The effects of load variation on multi-pulse ac to dc converters have been moreover investigated. This work showed a comparative study of multiple pulse converters.
\end{abstract}

Keywords- Harmonics, Multi-Pulse, Total Harmonic Distortion (THD), Power Quality, Ripple Content.

\section{I- INTRODUCTION}

$\mathbf{T}$ hree-segment managed rectifiers have a wide range of applications ranging from small rectifiers to high voltage direct current (HVDC) transmission systems. They are used for electrochemical strategies, a wide range of motor drives, controlled force rendering, traction gears and various applications. Switching methods can be specifically classified into two main categories: line-commuted controlled rectifiers and drive-commuted pulse width modified rectifiers. The 3- segment converter has some strategies specifically followed for the relief of harmonics and the multi-pulse converters fall into the same sort of solution action. Multi-pulse converters are essentially the most important answer to the harmonic problem in the three-segment converter process. With the advancement of technology, these converters and various electronic devices with built-in magnets provide the need for high-penetration first-rate and multi-industrial, commercial operations, with improved efficiency. Increasing the number of pulses from AC to DC converters directly changes its efficiency parameters such as wavelength, type element and total harmonic distortion.

Multi-pulse converters are converters that deliver more than six DC voltages per cycle from the AC input or compared to a six pulse bridge rectifier supply with a converter with additional stages in the AC. Phasemoving transformers are used to deliver large names from three-segment AC mains, using various combos of transformer windings such as delta, zigzag, polygon, fork and so on. In this thesis we will use zigzag transformers. Segment-shifting transformers play an important role in the efficiency of multi-pulse rectifiers.

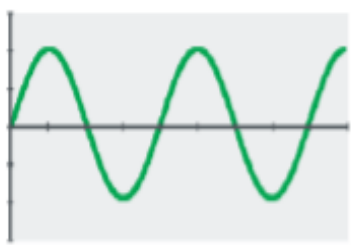

Sinusoidal Current

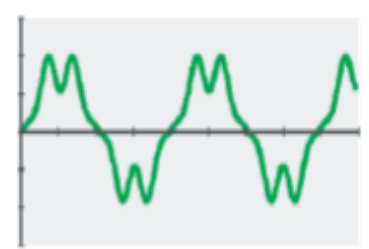

Non-Sinusoidal Current
Fig 1-Current waveform in harmonic (or nonlinear) loads 


\section{International Journal of Innovations in Engineering and Science, www.ijies.net}

Right-hand flow is generated by an electronic variablespeed drive, as in fig. Although the visual difference in the above waveforms is obvious, the graphical presence is adequate for the power engineer required for impact less analysis. Alone. Loads on the sinusoidal energy system. One method of describing a non-sinusoidal wave is called its Fourier series. Jean Fourier was a French mathematician in the early 19 th century who discovered the unique feature of periodic waves.

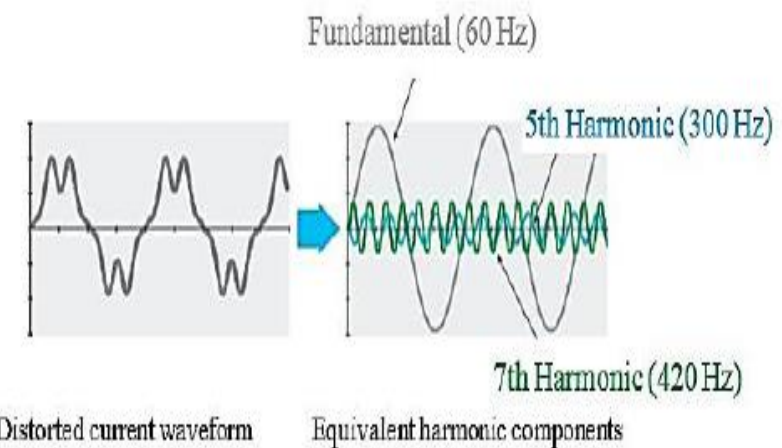

Fig 2-Current waveform in an electronic variable-speed drive

Fourier discovered that periodic waves could be represented by a series of simultaneous sinusoids. The frequency of these sinusoids is an integer of the frequency represented by the primary periodic wave. The wave on the upper left, for example, the sinusoid, is basically described because it has no melodic distortion. This example wave represents only three harmonic components, but some real-world waves (square wave, for example) require hundreds of sinusoidal components to fully explain it. The size of these sinusoids decreases with increasing frequency. Equivalent harmonic components actually represent the instantaneous flow as described by the distorted waveform that flows over the wire. This representation is necessary because it simplifies the analysis of the energy system.

The current drawn by the non-linear load passes through the impedance between the system source and the load. This current produces a harmonic voltage for each harmonic, which flows through the system impedance. These add harmonic voltages and basically produce a twisted voltage together. The magnitude of the voltage distortion depends on the source impedance and the harmonic voltage generated. Figure 3 shows how the twisted voltage is generated. As explained, nonlinear load is generally described as a source of harmonic current [1].

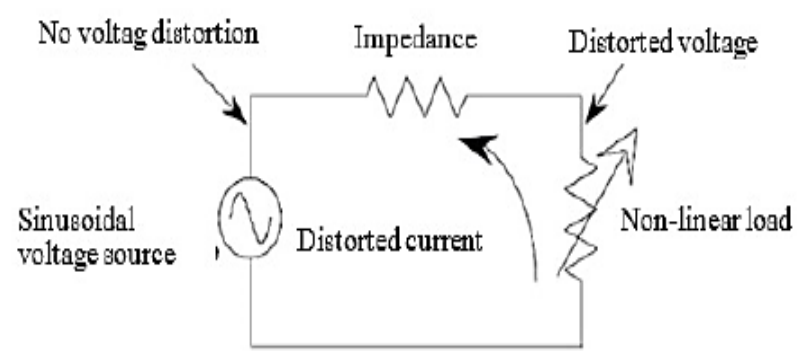

Fig 3-Creation of distorted current

\section{II-PROBLEMS RESULTING FROM HARMONICS}

There are many problems, which can arise from harmonic currents flowing in a power system. Harmonic Currents cause higher RMS current and voltage in the system, this can result in any of problems listed as below:

Table 1- Problems resulting from harmonics

\begin{tabular}{|c|c|}
\hline Equipment & Effect of Harmonics \\
\hline Motor & $\begin{array}{l}\text { Overheating, production of } \\
\text { non-uniform torque, increased vibration }\end{array}$ \\
\hline Transformer & Overheating and insulation failure, noise \\
\hline Switch gear and cables & $\begin{array}{l}\text { Neutral link failure, increased losses due to } \\
\text { skin effect and overheating of cables }\end{array}$ \\
\hline Capacitors & $\begin{array}{c}\text { Life reduces drastically due to harmonic } \\
\text { overloading }\end{array}$ \\
\hline Protective Relays & Malfunction and nuisance tripping \\
\hline $\begin{array}{c}\text { Power electronic } \\
\text { equipment }\end{array}$ & $\begin{array}{l}\text { Misfiring of Thyristors and failure of } \\
\text { semiconductor devices }\end{array}$ \\
\hline $\begin{array}{c}\text { Control \& } \\
\text { instrumentation } \\
\text { Electronic equipment }\end{array}$ & $\begin{array}{l}\text { Erratic operation followed by nuisance } \\
\text { tripping and breakdowns }\end{array}$ \\
\hline $\begin{array}{l}\text { Communication } \\
\text { equipment / PC's }\end{array}$ & Interference \\
\hline Neutral cable & $\begin{array}{l}\text { Higher Neutral current with 3rd harmonic } \\
\text { frequency, Neutral overheating and or } \\
\text { open neutral condition }\end{array}$ \\
\hline $\begin{array}{l}\text { Telecommunication } \\
\text { equipment }\end{array}$ & $\begin{array}{l}\text { Telephonic interference, malfunction of } \\
\text { sensitive electronics used, failure of } \\
\text { telecom hardware }\end{array}$ \\
\hline
\end{tabular}

\section{III- LITERATURE REVIEW}

1. "The Impacts of Harmonics Reduction on THD Analysis in HVDC Transmission System using Three-phase Multi-Pulse and higher Level Converters, Gbadega Peter . A A.K Saha. 978-17281-0369-3/19/\$31.00 @2019 IEEE.

In this paper eliminating the glitches confronted by High Voltage Direct Current (HVDC) transmission systems such as converting station and harmonic cost can therefore make it more realistic. Generally, total harmonic distortion can simply be lessen up to the allowable limits, just by increasing the pulses number in a multi-pulse converter. The mitigation methods of various converter levels during the operation of high 


\section{International Journal of Innovations in Engineering and Science, www.ijies.net}

voltage direct current (HVDC) transmission system are compared and its basically the essence of the paper. This study further investigates the impact of harmonic reduction on total harmonic distortion (THD) analysis of various converter levels. Hence, the paper presents the higher-level converters and different multi-pulse AC-DC (6-pulse, 12-pulse, 24-pulse and 48-pulses) converters in the HVDC transmission system to eliminate harmonics in the DC link with reference to IEEE 519 standards. More so, the increasing effect of the pulses number with respect to the AC-DC converters performance is analyzed. The only performance indicator used for the comparison of various converters is the THD values.

\section{2. "Power Quality Enhancement Using Current Injection Technique in a Zigzag Configured Autotransformer Based 12-Pulse Rectifier" $R$ Kalpana,. Khimavath Sai Chethana}

This paper proposes a DC side circuit configuration that improves the harmonic suppression ability of a 12-pulse diode bridge rectifier (DBR) using a zigzag configured autotransformer. The DC side circuit uses a 1-phase DBR along with interphase transformer which generates the required circulating current thereby modifies the DC currents at the DBR output, in turn shapes the input line current near to a sine wave. The proposed 1-phase DBR is connected in parallel with the load which enables to reuse the harmonic energy thus improving the energy conversion efficiency. The zigzag configured autotransformer used for 12-pulse DBR possesses the inbuilt ability to hinder the zero sequence components which expels the need of zero sequence blocking transformer. The proposed configuration is analyzed, simulated in MATLAB Simulink and the simulation results are presented, which confirms the reduction of THD in the input line current and thereby improving power quality under large load variations. Further, the viability of the proposed configuration is verified by experimental results which confirms the suitability of the proposed configuration in industrial applications.

3. "Modeling and Simulation of Multi-Pulse Converter for Harmonic Diminution", Urmil Desai, Darshan Rajesh Vora, 978-1-5090-4715-4/17/\$31.00 @2017 IEEE.

The concern of power quality now days is a major anxious area of research in the power sector.

With the innovation in the technology now it is possible to keep power sector free for the reduction of Total
Harmonic Distortion using different concepts and applications. This research paper deals with the diminution of Total Harmonic Distortion using Multipulse AC to DC Conversion scheme. Every such converter provides 6-pulse AC to DC conversion, so in order to create more sets of 6- pulse systems, a consistent phase-shift is required and hence with proper phase-shifting angle, 6, 12, 24, and higher pulse systems have been produced. The performance advance of multi pulse converter is achieved for total harmonics distortion (THD) in supply current. All the simulations have been done for similar ratings for all the multi pulse converters configurations. The results are obtained for uncontrolled converters for R Load.

\section{IV- APPLICATION GUIDE FOR SOLVING HARMONICS PROBLEMS}

Over the past few years, much effort has been put into reducing overall harmonic distortion using a variety of concepts and applications. In Figure 4, describe the various methods that are widely used for harmonics reduction. Harmonic therapy can be done in two ways, filtering or dissolving $[2,3]$. Several attempts have been made to reduce the harmonic content in the utility line currents of controlled converters [8]. Passive filters have been used in lots of experiments with unique configurations, but this method suffers from heavy, cumbersome filter out elements and once in a while resonance issues [9].

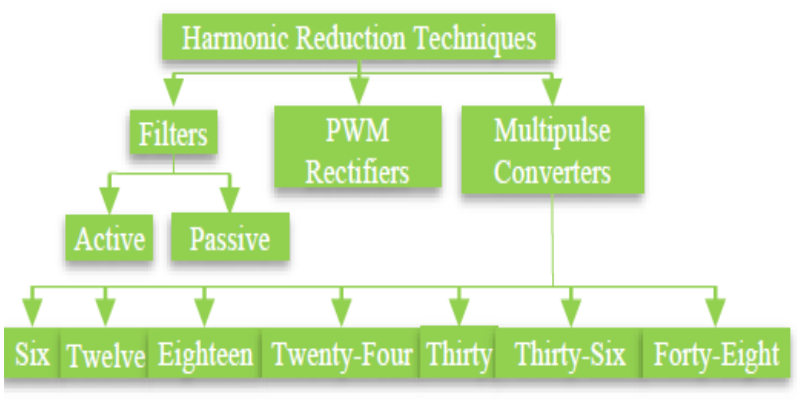

Fig 4- Various Harmonic Reduction Techniques

Active filters have been used in many researches and appear to be an interesting option, but this technology suffers from complexity and high cost [10]. Hybrid solutions the usage of energetic filters and passive filters are utilized in high-energy programs to improve passive filter overall performance. However, this technology is heavy, requires high cost, complex construction, is large and not immediately available from the manufacturer $[11,12]$. The principle of the multi-pulse converter is related to the lack of harmonics on the source side. This 


\section{International Journal of Innovations in Engineering and Science, www.ijies.net}

formula consists of the phase change of the input voltage and therefore the input voltage divided by the number of pulses. As the pulse number increases, the harmonics at the input decrease and the total harmonic distortion (THD) decreases. The use of a six-pulse diode bridge rectifier is an integral part of this system. The use of multi-pulse converters allows to reduce the size of the filter element. Multi Pulse Converter is an accessible configuration with high power ratings and high quality output waveforms. Bridge rectifier is the basic block required for AC-DC conversion; However, full wave and half-wave rectifiers are used up to a rating of $120 \mathrm{~kW}$ [2].

In recent years, high-power self-propelled AC-DC converters have become an integral part of many industry and power system applications, mainly due to their superior characteristics over traditional line commuted thyristor-based converters, such as reactive power flexibility. Lead to the ability to supply active power to weak or inactive networks.

The need to maintain high capacity forces these converters to be connected at high voltages, usually a few hundred kilowatts. 3-phase controlled rectifiers range from small rectifiers to large high voltage direct current (HVDC) transmission structures. They can be used for electro-chemical strategy, different types of motor drives, traction equipment, operated power supplies and different applications. In modern power electronics converters, a three-phase controlled converter is commonly used as a rectifier in electric utilities to control adjustable-speed drives (ASD) [4], [5] and regenerative power $[6,7]$. Done, Here we have solved the total reduction of harmonic distortion using the multi-pulse AC to DC conversion scheme.

\section{V- CONCLUSIONS}

The aim of the current work is to investigate the performance of controlled and uncontrolled multi-pulse converters. These converters are studied as the AC supply current, total harmonic distortion, ripple content and the harmonic spectrum of the form factor in the $\mathrm{AC}$ mains. It was therefore concluded that the performance parameters of these converters generally improve significantly as the number of pulses increases in the multi-pulse case.

\section{REFERENCES}

[1] V. Nedic and T. A. Lipo, "Low-cost current-fed PMSM drive system with sinusoidal input currents," IEEE Trans. Ind. Appl., vol. 42, no. 3, pp. 753- 762, May/Jun. 2006.

[2] W. Farrer, "Significant source harmonic reduction achieved using di-rect parallel connection of two 6pulse converters," Proc. Inst. Electr. Eng.-Electr. Power Appl., vol. 153, no. 2, pp. 167-176, Mar. 2006.

[3] K. Mukherjee, S. SenGupta, T. K. Bhattacharya, A. K. Chattopadhyay, and S. N. Bhadra, "Simplified analytical averaged model of a thyristorized commutatorless series motor," IEEE Trans. Ind. Appl., vol. 42, no. 6, pp. 1508-1515, Nov./Dec. 2006.

[4] A. I. Maswood, A. K. Yusop, and M. A. Rahman, "A novel suppressed-link rectifier-invertertopology with near unity power factor," IEEE Trans. Power Electron., vol. 17, no. 5, pp. 692-700, Sep. 2002.

[5] R. Naik, N. Mohan, M. Rogers, and A. Bulawka, "A novel grid interface, optimized for utility-scale applications of photovoltaic, wind-electric, and fuel263 International Journal of Science and Research (IJSR), India Online ISSN: 2319-7064 Volume 2 Issue 4, April 2013 www.ijsr.net cell systems, "IEEE Trans. Power Del., vol. 10, no. 4, pp. 1920-1926, Oct. 1995.

[6] N. Mohan, "A novel approach to minimize line current harmonics in interfacing renewable energy sources with 3-phase utility systems," in Proc. IEEE Conf. APEC, Boston, MA, Feb. 1992, pp. 852-858.

[7] N. Mohan, T. M. Undeland, W. P. Robbins, Power Electronics: Converters, Applications, and Design, 3rd Edition, 200219

[8] H. A. Pacheco, G. Jimenez, and J. Arau, "Optimization method to design filters for harmonic current reduction in a three phase rectifier," in Proc. IEEE Conf. CIEP, Puebla, Mexico, Aug. 1994, pp. 138-144.

[9] S. Bhattacharya, D. M. Divan, and B. B. Banerjee, "Control and reduction of terminal voltage harmonic distortion (THD) in hybrid series active and parallel passive filter system," in Proc. IEEE PESC, Seattle, WA, Jun. 1993, pp. 779-786.

[10] J. Ortega, M. Esteve, M. Payán, and A. Gómez, "Reference current com- putation methods for active power filters: Accuracy assessment in the frequency domain," IEEE Trans. Power Electron., vol. 20, no. 2, pp. 446-456, Mar. 2005. 